\title{
Out of the Dilemma, Wonderful Teaching-Some Viewpoints on Improving the Teaching Effectiveness of Ideological and Political Theory Course
}

\author{
Jie Li \\ Wenzhou Vocational \& Technical College, Wenzhou 325035, China \\ E-mail:289427730@qq.com
}

\begin{abstract}
Through years of teaching experience, I put forward true feeling, new views and live classroom to stimulate students' creative of moral thinking, so as to return to the realization of the main position of students in the ideological and political teaching and to improve the effectiveness of ideological and political course.
\end{abstract}

Keywords- ideological and political course; realistic question; scheme; effectiveness

\section{INTRODUCTION}

Many people sigh: now the classes in the university touch the soul lesson too little. In today's society, Ma Jiajue, Yao Jiaxin, and the students studying in Japan alert us of the events again and again: higher education cannot train the students of only professional skills, no moral emotion; only to escape and no responsibility. As the main channel of moral education in Colleges and universities, the main position of Ideological and political course is, "what kind of people to be cultivated", one class that of the leading thought, shaping the soul. The special function of the education and the important position are irreplaceable to any other courses.

\section{PRACTICAL PROBLEMS IN TEACHING}

I am engaged in the ideological and political course teaching for seventeen years, this is my circumstance encountered in the first class. I asked the students: "Do you like the ideological and political course?" $1 / 3$ of the students shake their heads, 1/3 students keep their silences, and 1/3 of the students pretend not to be heard. Not the students have some problems. For a long time, Chinese moral education is "upside down". In primary school, we talk about communism; in secondary school, we talk about socialism; at the University, we reinforce the citizen moral education for the students. The truths tell us, if the teachers pay too much attention to inculcate the ideological and political moral knowledge, neglect the emotional factors of students, view their students as "virtue bag" and regard "obedient" as a successful sign of moral education, simply equate between master and identity. The students are lost in the vast empty didactic theory, and then the students' learning is not the rich experience and the wisdom of life, but the barren moral language and knowledge of bubble. This "the knowledge not people" teaching is an undoubtedly failure.

\section{SOLUTIONS}

\section{A. True Emotions to Open the Door of Students}

The so-called "real" is true faith, really understand, true feelings. Teachers' knowledge is the "truth"; classroom pays "really"; treat the students with "true feelings".

Teaching as a good teacher, good teaching is inferior to music teaching. A prerequisite to a good ideological and political education is the teacher himself really believes true faith, really understands Marx theory, including the truth to the teaching of ideological and political course. Once, referring to the traditional Chinese moral culture, a boy says: "teacher, these things are out of date, that should be put into historical museum to display." I talk with the students by taking a clearcut stand, "now many young people are keen on the QQ chatting, KFC, McDonald, the movies, but forgotten the excellent traditional culture. I recommend Chinese traditional culture. Self-cultivation, regulating the family, country and the world, are the essence of the national, and are also the essence of world culture. Britain published a book called "Encyclopedia Britannica" in 1999. The first page is a philosopher in the Spring and Autumn Period, the second page is Confucius, the third pages is Socrates, the fourth page is Platoon. A highly respected Confucianism culture entrepreneur Shibuzawa Eichi in the Japanese business community thinks, Japanese companies should be established on the basis of the abacus and the Confucius Analects. Training class read by the Singapore students is the Chinese traditional ethics. President of Singapore has announced that the Confucian spirit is Singapore's ruling class. Once in Paris gathering the world's 75 Nobel winner, they issued a joint declaration, humanity will survive in twenty-first Century, that should go back to 2500 years ago, to draw Confucius wisdom. Chinese traditional culture now is not out of date, and it will not become obsolete. Take the spirit of "taking students as the foundation, through reasoning to persuade, moving people by Emotion" as a principle, the teaching course is a language communication course among teachers and students who act as equivalent individual. I put forward the "Ternary Incremental Method" moral teaching in the teaching of ideology and politics, The Ternary Incremental Method is shown in Figure1. Only we give the students the idea that" touching in mind, sentiment in thought, reflecting in action" in step by step, the teaching process of ternary incremental method is shown in Figure 2. 
The teachers should emphasize the students' individual

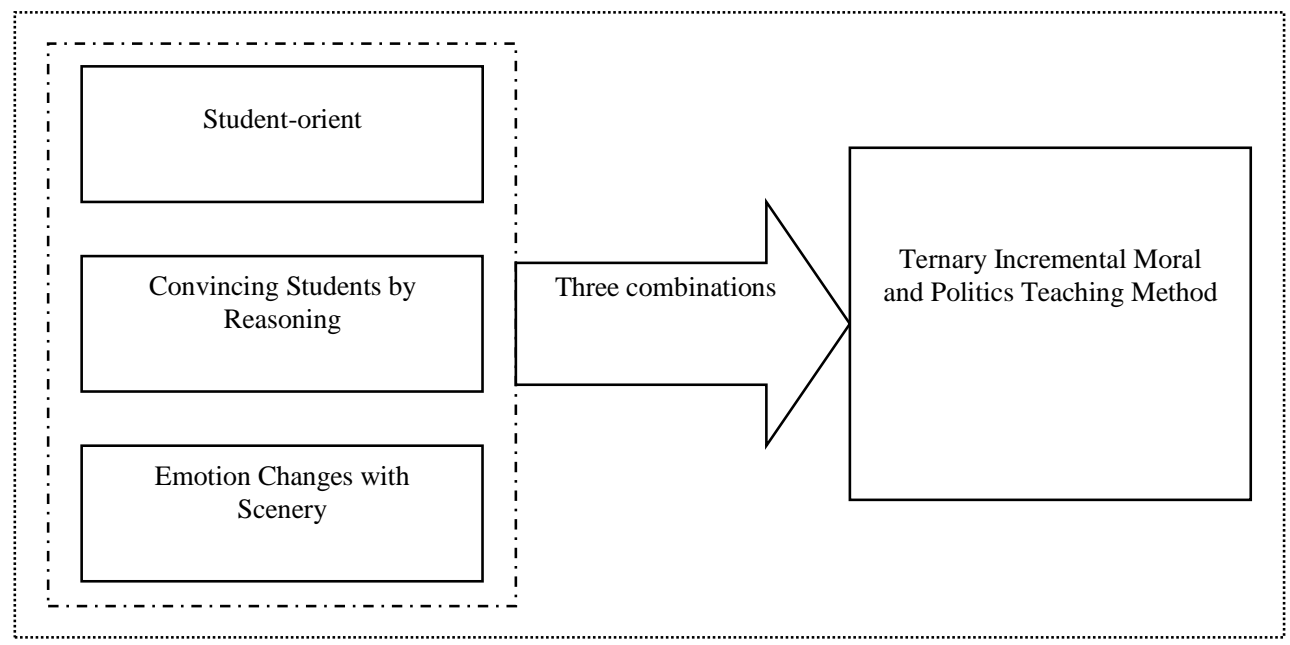

FIGURE I. TERNARY InCREMENTAL MORAL AND POLITICS TEACHING METHOD

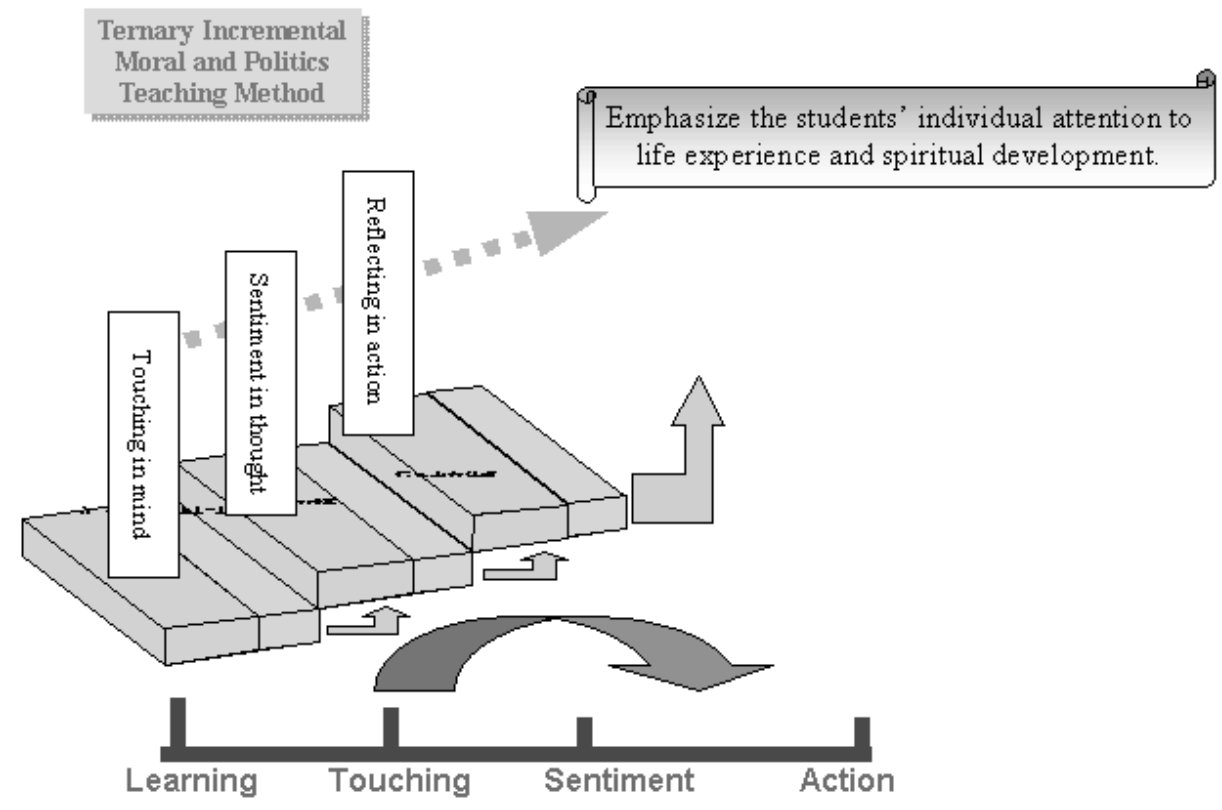

FIGURE II. The TeACHING PROCESS OF TERnARY INCREMENTAL METHOD

attention to life experience and spiritual development.

In order to prepare a lesson, I usually take days. Sometimes, I will order a selection of materials, and think the exact expression of certain words for a long time. Because I know clearly, persuading the students firstly is to convince myself. I often wonder the questions. How to use a better way to impart more knowledge to the students? I often ask myself. When students get disheartened, can you arouse their confidence? When students are apathetic, can you make them up? When a student is at a loss on what to do, can you give them inspiration? So for me, it is a lesson from negative to positive and then to negative and to affirmative final, which a process of tough and development. The process of teaching to carry on instructional activities changes with development of human civilization and technology widely used and programmed in current instruction.
On the achievements of socialist construction and the patriotic content, if the teacher's language is rigid, it may make the students feel boring. When it comes to China's vast territory, I described as follows. When you are in the map of the world, the first thing you can see is the ocean, the Pacific; the largest continent in Pacific Coast is Asia; and the largest country in Asia is China. The land here is almost as big as the whole of Europe. It is the equivalent of 40 English, 17 French, 26 Japanese, walking along the equator along our borders, almost equal to a circle around the earth. Our country is vast. When most north of Heilongjiang Mohe County has been in miles, the southernmost tip of Hainan Island is still a piece of a wild profusion of vegetation in the summer sun sight; when the east coast of the East China Sea fishermen are facing the sun sea fishing, most Western Pamir Plateau on the herdsmen are still in the deep sleep......". Vivid language gives the students make 
sense of beauty and emotion. Teachers only use his feelings to ignite the students' enthusiasm, arouse students' emotional resonance. In order to achieve the purpose of love the passion to love education, only the teachers use their true feelings to ignite the enthusiasm of the students. "Touching is the heart, not the first case." Every time I came into the classroom, looking at a picture of youth face, I seemingly calm exterior, which is always difficult to curb the inner sense of excitement, no matter what the troubles and grief in heart. All of them disappear in smoking. I am full of passion to the rostrum. I know only on my own with confidence, full of pride and passion with propaganda truth, I will take the feelings to pass them to each student, to infect every student, arouse students' emotional to increase students' interest in learning.

\section{B. New Views to Enlighten the Students' Thinking}

If the teacher wants to win the students' respect, they must be constantly on their original knowledge to be added and to be updated. The knowledge teaches by the teachers must meet the psychological characteristics of the students, to face the reality, rich sense of the times. The students are interested "Xi Li Ge", "sister HOLD" "Happy Boys" and "super singing girl" these words, which can become my lecture topic. But we should pay attention to guide. Basic knowledge of ideological and political education contains the socialism theory and the Marx doctrine in the content; it also contains the philosophy, history, sociology, ethics and other related knowledge. In the process of teaching, the teacher should coordinate closely with students to help them reach a high level of mastery-not only understanding but also internalizing and practicing the principles. A teacher should have good knowledge structure, is not limited to book knowledge. Famous quotes, historical allusions, and material encountered in life, can be flexibly to load one's pages with references in teaching and arouse students' thinking, make them be inspired in the knowledge and interest. Once, I overheard a passage by a radio in the school bus, which set people to thinking, I after thinking laugh, and after their processing I speak to students in the classroom. Now in the society, some things are more and more, and some are less and less, such as the Xun Zhou is know more and more, but the Lu Xun is known less and less; the Bill is known more and more, but the Paul is known less and less; the premarital cohabitation is known more and more, but the cohabitation after marriage is becoming smaller and smaller; more and more in writing books, but less and less in reading a book; more and more tricks, fewer and fewer craftsmen...... In the students' thinking at the same time, it is timely to guide them with the dialectical viewpoint, and help them to establish a healthy outlook on life and value. The student's questions in class, generally is their true feelings. I never run away from the facts, evade the crucial point, always tell the students the reality and guide them to distinguish right from wrong and give them a satisfactory and convincing answer. We should cultivate the students' spirit of exploration, rational thinking and innovative ability. Teachers hold the students' mind step by step, get the feedback information timely and adjust from the student's gaze and expression timely to realize the interaction. Some people say that the ideological and political theory course is "the class", the teaching material and content $f$ our higher vocational students are the same to those of university students, which lack of time and pertinence. Given the textbooks, as the "three close to" principle, i.e., closer to the era, close to reality, closer to the students, I use the teaching "previewing before class to search for knowledge, reading newspapers to find hot pints at extracurricular, focusing on participation by teachers in class, focusing on debate, researching the difficulty after class and combining the research with the teaching mode. Teaching reform not only means the reform of teaching methods, but also the reform of teaching methodology, whose focus is not teaching methods but the relationship between teaching methods and teaching objects. Therefore, it is trying to explore the theoretical basis behind teaching methods. Teachers pay attention to the popular things among the students and in society and as well as use a variety of new things, such that cause a students' thinking. Let the social hot spot and hot spot theory in the first time come into the classroom. Even if the afternoon, the new teaching material that found at morning will be updated in a timely manner. The ideological and political education always stands in the forefront of the times, in order to better guide students.

\section{Live Classroom let the Theory "Thaw"}

A melodious music, a wise famous quote and a debate that shines wisdom and spark, my classes often prelude in this atmosphere.

In teaching, I use the traditional teaching in one way, in imparting knowledge of the "teachers" at the same time, just help students more as a "teacher". Teachers can make full use of the characteristics of audio and video data to improve the attraction and infectivity of course, let the cold theory has a warm the heart of power. Keynote speech, press conference and classroom debates have become my classroom content. The dilemma of case teaching is commonly used in my teaching methods. I put forward the moral and legal dilemma in society, and then I let the students discuss, let them tell their own points of view, and then to review the solutions. In the discussion of classroom teaching, the teachers must create democratic, equal relationship of between teachers and students, and create a relaxed, harmonious classroom atmosphere. They should try their best to "Relax to Teaching, happy to learning"; which fills full feelings, emotional experience and life communication in the classroom.

The reception theory and the training can be gotten by the students in the discussed process of moral dilemma. In the choice of cases, I follow the following principles: first, to highlight the oriented thing, seize the puzzle in the ideology of students. Secondly, to highlight the fun, seize the students' excitement thoughts. To select something that students with certain concerns, teachers can stimulate students' interest. Combined with dynamic focus on their inner needs and moral education goal, the students can achieve the excitation state timely. Finally, we should highlight the openness, and seize the limited point of students' ideological. Teachers pass on to student's knowledge through the process of teaching and the process of teaching and learning is a game between teachers and students. In order to give the students more thinking space, we should create a good discussion and atmosphere, learn to the rational analysis, give a variety of answers to the selected case, and overcome the limitations and the sidedness of thought. For example, two-year-old girl Yue Yue was crushed in 2011 at Foshan, the first day of publishing the news by media, at the second day I let the students discuss in the classroom. The 
students are all filled with righteous indignation, fierce. Some students said: "Chinese economic growth is remarkable; the security situation of Chinese food is striking; the collapse of Chinese moral civilization is amazing. The China is known as harmony and prosperity, it is the second biggest economy in the world. However, the moral system of the society has total collapsed. Some students said: "these people are poikilotherm, just wasting for the people". Even some students contact me the case of the Tianjin Xu Yunhe, Nanjing Peng Yu once I had told them. They said: "this kind of indifference ashamed the Chinese, he is sad for himself as a Chinese and." It seems the students' moral is not very clear, but it did not reach the discussion but blindly appeared to blame. I further question: "if you are the nineteenth passers-by, what would you do?" In the context of the design, the students began to calm down, ask their hearts. I also guide them as follows: the Little Yue Yue event is enquired of bystander's moral, but also it cannot reach a universal conclusion on moral turpitude. After all, in the misery behind, the spectator has his indifference to designed system and environmental hazards. Every one of us needs to read: before we criticize others, can we confident that he is not apathy to come? I'm afraid we have high moral standards on people sometimes, but easy to us. Our society needs criticism, but we need more change and ascension for everyone "social morality", which is as a humble but noble strength. I'm not simply in the pursuit of the completion of teaching tasks, but the thinking process of how to get the conclusions. I usually cultivate the students at the correct moral judgments for the moral issues and the ability of questioning and solving the problems, I will provide "shooting targets" for students, correct "shooting direction", and provide a scientific "shooting method", I should be good at accurate "award", thinking process of how to get the conclusions is shown in Figure 3. So as to provide basic necessary qualities into the community in their future.

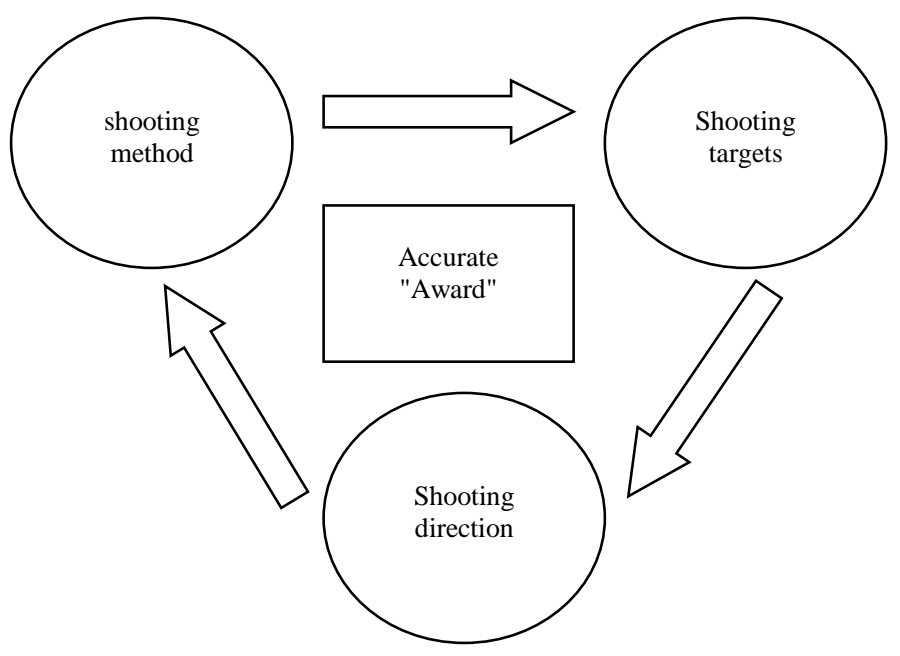

FIGURE III. ThINKING PROCESS OF How To GeT CONCLUSIONS

\section{THE EFFECT OF TEACHING}

My teaching implements three change: to change the traditional cross transmission for interactive type; to change the study of theory teaching to research of problem; to change the single oral teaching to a variety of teaching methods. I am in the teaching of ideology and politics for seventeen years, I was praised by Shunting leadership because of teaching; I also made a statement in the province forum as the school representative; this year I was elected as the students' favorite teacher in our teaching at the first school. I truly feel that college moral education is not empty, boring sermons. It should be affectionate with vivid new and innovative teaching methods, and make the knowledge and ability of students, thought and practice complement with each other. The ideological and political class can also be very exciting. Whenever passing through the last class in the term, I hear the students to say: "teacher, I hope to hear your ideological and political course next semester." And they give me a warm applause, which really made me very happy.

Ideological and political education for students is not only the concept, principle, objective, but also it should be more theoretical thinking on social observation, basic standpoint, viewpoint and method. I also know the responsibility and pressure of the platform. What we do may be just a word of commendation, a smile, and probably a lifetime incentive given for the student.

\section{REFERENCES}

[1] Li Jie, Application of Dilemma Discussion Teaching Method in University Moral Course, China Higher Education Research, 2004, 4.

[2] Wang Qin, New Methodology of Ideological and Political Education[M], Zhejiang University press, 2003.

[3] Luo Guojie, Ethics, Chinese people's Press, 1989.

[4] Zhan Wansheng, an introduction to the overall construction of moral education system", Education Science Press, 2001.

[5] Zheng Xiaojiang, Traditional Morality and contemporary Chinese society, Anhui Education Press, 1998.

[6] Li Zheng, LinN Feng, A Theoretical Discussion of Undergraduate Research, Tsinghua Journal of Education, 2009, 30(4):95-101

[7] LI Zheng-tao, From Teaching Method to Teaching Methodology Methodology Transition in the Process of Modern Teaching Transformation, Theory and Practice of Education, 2008, 28(11):32-36. 